\title{
A produção científica e o desenvolvimento de tecnologia da cadeia produtiva da
}

\section{apicultura}

\author{
Scientific production and the development of technology in the production chain of beekeeping \\ Producción científica y desarrollo tecnológico de la cadena de producción apícola
}

Recebido: 14/09/2021 | Revisado: 30/09/2021 | Aceito: 03/10/2021 | Publicado: 04/10/2021

\author{
Mirelle Juliana Marque \\ ORCID: https://orcid.org/0000-0001-7057-0277 \\ Universidade Estadual de Montes Claros, Brasil \\ E-mail: mirelle_marques@yahoo.com.br \\ Júlia Rodrigues Ortega \\ ORCID: https://orcid.org/0000-0002-7100-1890 \\ Universidade Estadual de Montes Claros, Brasil \\ E-mail: juliarortegar@gmail.com \\ Vanessa de Andrade Royo \\ ORCID: https://orcid.org/0000-0002- 4842-3569 \\ Universidade Estadual de Montes Claros, Brasil \\ E-mail:vanroyo31@gmail.com \\ Afrânio Farias de Melo Jr \\ ORCID: https://orcid.org/ 0000-0001-7899-3979 \\ Universidade Estadual de Montes Claros, Brasil \\ E-mail:afraniafariasdemelo@gmail.com \\ Dario Alves de Oliveira \\ ORCID: https://orcid.org/ 0000-0002-8161-4607 \\ Universidade Estadual de Montes Claros, Brasil \\ E-mail:dario.aol@unimontes.br \\ Elytania Veiga Menezes \\ ORCID: https://orcid.org/0000-0003-2574-9360 \\ Universidade Estadual de Montes Claros, Brasil \\ E-mail:Elytania.menezes@unimontes.br
}

\begin{abstract}
Resumo
O agronegócio apícola tem se destacado por estar em plena expansão, preenche os requisitos de sustentabilidade, gera renda e contribui para um meio ambiente equilibrado. Este trabalho procura apresentar a evolução da apicultura no período de 2000 a 2019com análises de publicação de artigos científicos e também do cenário de proteção por meio de depósitos de documentos de patentes dos produtos e processos oriundos da cadeia apícola no cenário nacional e internacional. Para tanto, foram realizadas buscas de publicações científicas na base de dados da Web of Science e das proteções de tecnologias nos bancos patentários do Instituto Nacional da Propriedade Industrial (INPI), Escritório Europeu de Patentes (ESPACENET) e no Escritório Latino Americano de Patentes (LATIPAT). Os resultados permitiram observar um quantitativo de 21.961 publicações de artigos e um conjunto de 11.292depósitos de documentos de patentes. A China é o maior produtor de conhecimento de acordo com os bancos de dados no período estudado. No Brasil, o maior gerador de conhecimento científico relacionado aos produtos apícolas são os depositantes independentes, seguidos pelas Universidades públicas, com publicações voltadas na maioria para a saúde. Os resultados obtidos na pesquisa demonstram que a apicultura é uma atividade lucrativa, principalmente nos países asiáticos que exploram todos os produtos apícolas e possuem apoio da iniciativa privada.
\end{abstract}

Palavras-chave: Cadeia produtiva; Produtos apícolas; Agronegócio.

\section{Abstract}

The beekeeping agribusiness has stood out for being in full expansion, fulfills the requirements of sustainability, generates income and contributes to a balanced environment. This work seeks to present the evolution of beekeeping in the period from 2000 to 2019 with analysis of the publication of scientific articles and also of the protection scenario through the filing of patent documents for products and processes from the bee chain in the national and international scenario. For this purpose, searches for scientific publications were carried out in the Web of Science database and technology protections in the patent banks of the National Institute of Industrial Property (INPI), European Patent Office (ESPACENET) and in the Latin American Patent Office (LATIPAT). The results allowed to observe a quantity of 21,961 publications of articles and a set of 11,292 deposits of patent documents. China is the largest producer of knowledge according to databases in the period studied. In Brazil, the greatest generator of scientific knowledge related to bee products is the independent depositors, followed by public universities, with 
publications mostly focused on health. The results obtained in the research demonstrate that beekeeping is a profitable activity, especially in Asian countries that exploit all bee products and have support from the private sector.

Keywords: Productive chain; Bee products; Agribusiness.

\begin{abstract}
Resumen
La agroindústria basada en la apicultura se ha destacado por estar en plena expansión, cumple con los requisitos de sostenibilidad, genera ingresos y contribuye a un ambiente equilibrado. Este trabajo busca presentar la evolución de la apicultura em el periodo de 2000 a 2019 con análisis de publicación de artículos científicos y también del escenario de protección a través de documentos de patente de productos y procesos de la cadena apícola en el escenario nacional e internacional. Para ello, se realizaron búsquedas de publicaciones científicas en la base de datos Web of Science y de protecciones tecnológicas em los bancos de patentes del Instituto Nacional de La Propiedad Industrial (INPI), la Oficina Europea de Patentes (ESPACENET) y la Oficina Latinoamericana de Patentes (LATIPAT). Los resultados permitieron observar una cantidad de 21.961 publicaciones de artículos y un conjunto de 11.292 solicitudes de documentos de patente. China es el mayor productor de conocimiento según las bases de datos en el período estudiado. En Brasil, el mayor generador de conocimiento científico relacionado con los productos de las abejas son los depositantes independientes, seguidos por las universidades públicas, con publicaciones centradas principalmente en la salud. Los resultados obtenidos en la investigación muestran que la apicultura es una actividad rentable, especialmente en los países asiáticos que explotan todos los productos apícolas y cuentan con el apoyo del sector privado.
\end{abstract}

Palabras clave: Cadena de producción; Productos apícolas; Agronegocios.

\title{
1. Introdução
}

O agronegócio é considerado um setor de grande importância na economia, representa um terço do produto interno bruto. Entretanto há tempos possui como desafios a identificação e promoção de atividades produtivas que além de inovadoras, contribuam na propagação de tecnologias direcionadas aos pequenos produtores (Monteiro et al., 2015).

Os produtos apícolas têm alcançado o mercado mundial com crescimento no consumo que é percebido ano após ano. Caracterizado como uma atividade sem impactos ambientais, por necessitar do meio ambiente equilibrado para se desenvolver, diferindo da maioria das atividades rurais. Além disso, contribui com a economia por gerar emprego e renda, com o aspecto social, com mão de obra familiar, diminuindo o êxodo rural (de Souza, et al., 2016).

Por meio das atividades apícolas são desenvolvidos, há anos, produtos de grande relevância quando comparados a outras atividades agropecuárias (Vidal, 2018). Produtos como a geleia real, a cera, o pólen, a apitoxina, própolis e méis monoflorais que possuem alto valor agregado (Queiroga, et al., 2015; Viera \& Fernandes, 2016; Burgut, 2019; Wolf, 2018). Portanto, com o aumento da demanda faz-se necessário o desenvolvimento de técnicas apropriadas pelos apicultores para alavancar a produção máxima da colônia (Martinez \& Soares, 2012; Fernandes Junior \& Silva, 2016).

Um dos aspectos essenciais para a competitividade é o desenvolvimento não só científico e tecnológico, mas também econômico e também a capacidade de geração de inovações pelos países. O benefício das inovações reverte-se para todas as organizações, as quais se configuram como fator fundamental para a manutenção das atividades e geração de vantagens competitivas sustentáveis (Conto et al., 2016). O conhecimento da produção científica permite acompanhar e verificar em quais instituições e países é desenvolvido atividades científicas em determinada área do conhecimento.

Frente ao exposto e ao considerado potencial e importância dos produtos oriundos do uso sustentável da cadeia apícola para as instituições envolvidas e para o desenvolvimento tecnológico e econômico do país, o presente trabalho buscou analisar o cenário de publicações científicas e de desenvolvimentos de tecnologias por meio da identificação de artigos científicos e de documentos de patentes da área em bases de dados específicos.

\section{Metodologia}

As pesquisas foram realizadas nas bases de dados Web of Sciense, e nos bancos de dados de patentes do Instituto Nacional da Propriedade Industrial (INPI), Escritório Europeu de Patentes (ESPACENET), e no Escritório Latino Americano 
de Patentes (LATIPAT). Com utilização de palavras-chave: mel, mel abelha, mel apícola, mel apicultura, propolis, propolis apicola, cera, cera abelha, cera de abellha, cera apicolas, pólen, pólen apícola, geléia real e apitoxina. (Vieira et al., 2020)

Após a compilação de dados foram elaborados gráficos que revelam a evolução dos últimos dezenove anos (2000 a 2019) de depósitos para cada produto apícola, sejam: mel, própolis, cera, geleia real, pólen e apitoxina.

Foram identificados os principais países detentores da tecnologia, a produção e áreas de aplicação dos produtos de acordo com a Classificação Internacional de Patentes (CIP) e a situação legal dos pedidos de patente junto à base de dados do INPI. As atividades de identificação e processamento das informações foram realizadas no período compreendido entre outubro de 2019 a fevereiro de 2020, ambas sem delimitação temporal para recuperação dos dados.

\section{Resultados e Discussão}

As patentes e os artigos são meios de conhecimento tecnológico e científico. Se diferem por um passar ao titular o direito de propriedade e o outro o direito de acesso e uso. No entanto, os dois precisam de validação por avaliadores. A divulgação de artigos se dá por publicações referendadas em revistas científicas e as patentes por sua vez, dependem de depósitos do documento contendo a descrição da invenção a ser patenteada em instituições capacitadas (Mueller \& Peruccchi, 2014).

\section{Produções científicas referente aos produtos apícolas na base de dados Web of Science.}

Em análise aos dados recuperados na base de dados da Web of Science, foram encontrados 21.661 artigos científicos publicados referentes aos produtos da cadeia apícola. Dentre o total de documentos encontrados, 10.589 referem-se ao mel, 4.852 ao pólen, 4.280 a própolis, 1.026 a cera, 888 a geleia real e 29 a apitoxina.

Foi observado que no ano de 2019, as publicações científicas referentes aos produtos apícolas selecionados, atingiram seu ápice. O mel, é o produto apícola que mais originou pesquisas científicas, no período estudado, no ano de 2019, foram 1.067 publicações. O pólen e à própolis tiveram 504 e 531 publicações respectivamente no referido ano. Em seguida observase que as primeiras publicações científicas referentes à cera, geleia real e apitoxina iniciaram no ano de 2006, no entanto, assim como os demais produtos da cadeia apícola se destacaram no ano de 2019, com 152, 97 e 05 publicações respectivamente.

Dentre as Instituições que desenvolveram pesquisas científicas utilizando produtos oriundos da cadeia apícola, United States Departament of Agriculture (USDA), Universidade de São Paulo (USP) e University of California System (UCLA) são os principais produtores de conhecimentos científicos na área. Além dos líderes acima, foram observadas atividades científicas desenvolvidas pelo Centre National de La Recherche Scientifique (CNRS), Universidade de Illinois (UI), Chinese Academy of Agriculture Science (CAAS), Universidade Estadual Paulista (UNESP), Universidade Estadual de Campinas (UNICAMP), Bulgarian Science Academy (BAS) e Conselho Nacional de Investigações Científicas e Técnicas (CONICET) (Gráfico 1).

Os dados apresentados permitem observar que as maiores produções científicas são oriundas de instituições voltadas para a pesquisa, principalmente estrangeiras, sem atuação de empresas. Além dos resultados apresentados, há dezenas de outras instituições que propagam conhecimento por meio de pesquisas científicas, que no momento seria inviável a citação do nome de cada uma delas (Web of Science; 2020). Outro dado importante se refere as publicações de artigos científicos, oriundos de residentes no Brasil, concentradas nas Universidades que se localizam no estado de São Paulo. Caracterizado como o maior polo industrial e econômico do país. Tal resultado demonstra a contribuição das Universidades brasileiras para o avanço tecnológico do país. 
Gráfico 1. Instituições com maior número de artigos publicados entre 2000 e 2019.

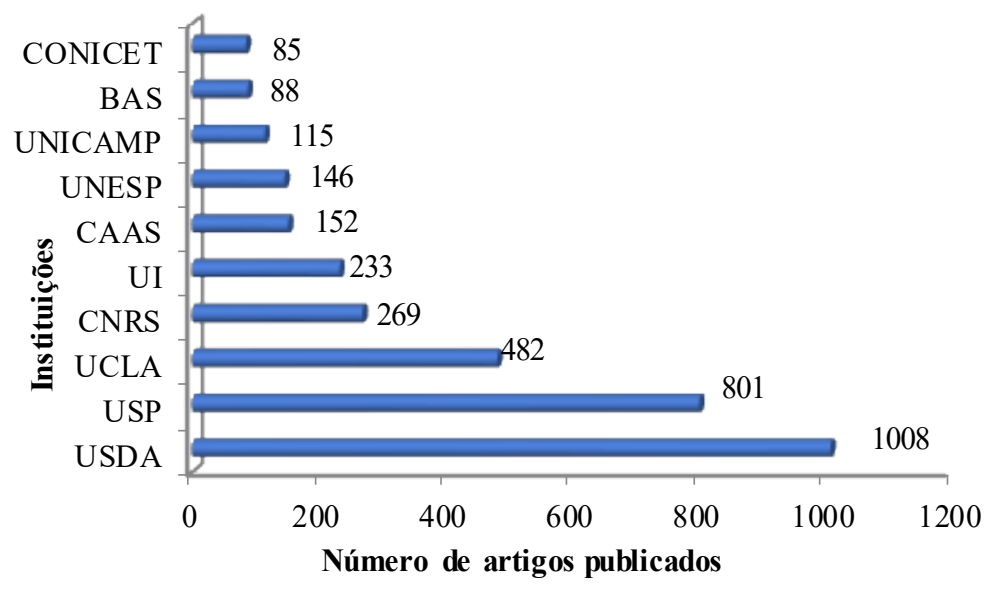

Fonte: Web of. Science 2019 e 2020.

A partir da pesquisa de classificação dos documentos selecionados, é nítida a multidisciplinaridade das publicações. A Entomologia lidera as publicações que abrange todos os produtos da cadeia apícola, no entanto, nas publicações com utilização de apitoxina, mel e geleia real ocupam respectivamente as primeiras e segundas posições. Os produtos apícolas citados também possuem publicações nas áreas farmacológica, ciência multidisciplinar e ciência dos alimentos respectivamente. Dentre estudos realizados nas áreas citadas, Adaskeviciute, et al. (2019) demonstra que o pólen apícola, além de ser um alimento rico em nutrientes e possuir propriedades antioxidantes, é rico em flavonoides. O estudo de Iegaki, et al. (2020), revela que a geleia real contribui para a saúde mental, melhorando a depressão induzida pelo estresse. Já Pascoal, et al. (2019) estudaram o efeito terapêutico da apitoxina para tratar doenças inflamatórias crônicas, como artrite reumatoide, tendinite, bursite, doenças da pele e até distúrbios neurológicos.

As publicações estão distribuídas de acordo com a matéria prima apícola utilizada. Na área de Ciências dos Alimentos e Farmacologia foram utilizados o própolis e apitoxina. As publicações com utilização de cera estão concentradas em Ciência dos Alimentos e Química Analítica. A área Entomologia ocupa 36\% dos artigos publicados, seguido por Ciência Multidisciplinar com 1428 publicações que equivale a 26\% do total e a Tecnologia da Ciência Alimentar com 1.061 publicações ou $20 \%$ do total de artigos (Gráfico 2). 
Gráfico 2. Publicações de artigos científicos de acordo com a classificação, no período de 2000 a 2019.

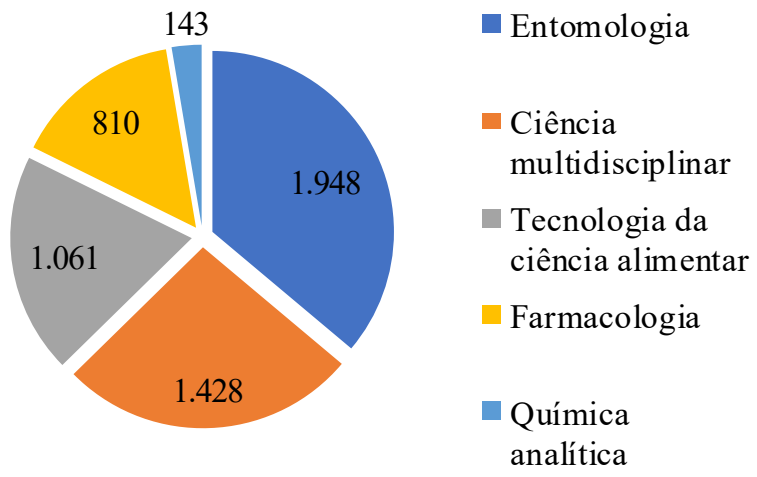

Fonte: Web of Science 2019 e 2020.

Os resultados obtidos na pesquisa revelam o quanto são distintas as áreas que utilizam produtos da cadeia apícola para desenvolvimento de artigos científicos. Em sua maioria essas pesquisas focam nas propriedades nutritivas e ação terapêutica dos produtos (Iegaki, et al., 2020; Pascoal, et al., 2019). No entanto, é possível observar que muitos pesquisadores têm voltado à atenção para a sanidade dos polinizadores, entre eles as abelhas. Com isso é demonstrado preocupação com os efeitos tóxicos dos inseticidas para as espécies, bem como as doenças que contribuem para o declínio de colmeias, oriundas da presença de vírus, bactérias e/ou outros patógenos (Romero, et al.,2019; Bommuraj, et al., 2019).

\section{Produtos registrados no Instituto Nacional da Propriedade Industrial}

O depósito de patente é um meio de proteção após o desenvolvimento de uma nova tecnologia e sua concessão pelo órgão responsável garante ao titular o direito de exclusividade. Além da possibilidade de retorno financeiro gasto no desenvolvimento dos produtos e processos. As patentes são classificadas em patentes de invenções ou patentes de modelo de utilidade. A proteção por meio de patente de invenção é utilizada quando a tecnologia origina um novo produto e a patente de modelo de utilidade é a forma de proteção utilizada quando são aperfeiçoados produtos ou objetos já existentes (INPI, 2020).

A partir da pesquisa dos documentos recuperados Instituto Nacional de Propriedade Industrial (INPI) compreendidos no período de 2000 à 2019, foram selecionados 315 documentos de patentes, dos quais, 138 para própolis, 129 para o mel de abelha, 31 cera, 8 para pólen, 5 para geleia real e 4 documentos para apitoxina.

Houve oscilações dos números de patentes depositadas no período estudado referentes à produção e utilização dos produtos apícolas e tecnologias correlatas. É possível observar que não houve depósitos de documentos de patentes entre os anos 2010 a 2011 para o produto mel. A utilização do pólen para produção produtos e processos iniciou em 2007, no entanto, nos anos 2009 a 2013 não houve depósitos de pedido de patentes e foi observado períodos sem depósito de patentes de produtos desenvolvidos com utilização da cera (Gráfico 3). Não foram recuperados resultados para o ano de 2019 e os documentos observados no ano de 2018 podem não corresponder ao número total, visto que a Lei de Propriedade Industrial garante ao depositante o sigilo pelo período de 18 meses, a partir do depósito. 
Gráfico 3. Números de depósito de patentes no Brasil, sobre o mel e tecnologias correlatas entre 2000 e 2019.

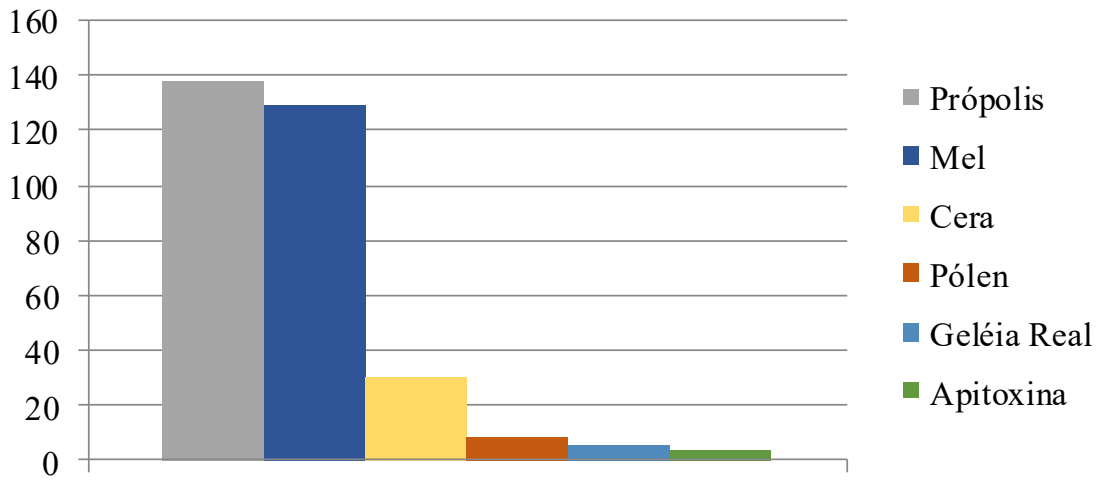

Fonte: INPI 2019 e 2020.

A maioria dos depósitos de pedidos de patentes realizados no Brasil utiliza mel e própolis como matéria prima, e não considera o grande potencial terapêutico e econômico dos outros produtos apícolas como a geleia real, o pólen a cera e a apitoxina. Do total de patentes depositados entre os anos de 2000 a 2019, 42\% foram requeridos por depositantes independentes, seguido por $30 \%$ solicitados por Universidades, as empresas solicitaram apenas $17 \%$ dos pedidos de patentes. As parcerias representam 11\% dos pedidos de patentes depositados no período de 2000 a 2019 (Gráfico 4).

Gráfico 4. Distribuição de patentes relacionadas aos produtos da cadeia apícola no período de 2000 a 2019 por tipo de depositante.

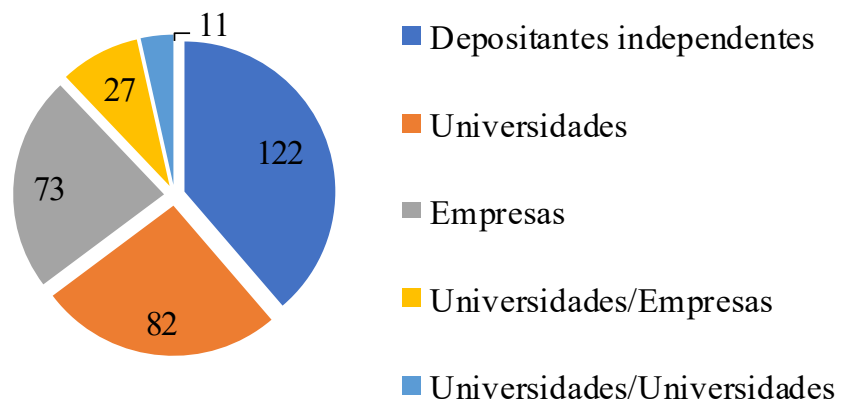

Fonte INPI, 2019 e 2020.

Em se tratando de análise dos resultados referente a empresas seja ela pública ou privada, é possível observar que possuem o menor número de depósitos de patentes. Esse fato está relacionado com a falta de investimento de empresas privadas em inovação, os investimentos em sua maioria são feitos pelo poder público e concentram-se nas universidades (Gráfico 5). 
Gráfico 5. Instituições brasileiras que possuem pedidos de patentes relacionados aos produtos da cadeia apícola no período entre 2000 e 2019.

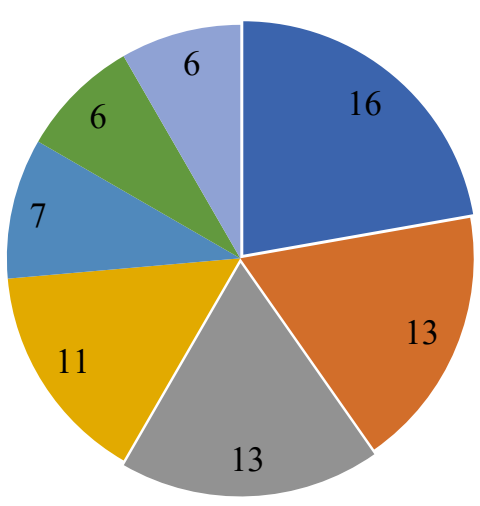

- Universidade Federal de Alagoas

- Serviço Nacional de Aprendizagem Industrial

- Universidade Estadual do Maranhão

- Universidade Federal do Paraná

- Instituto de Tecnologia e Pesquisa/SE

- Universidade São Paulo

Universidade Federal do Ceará

Fonte: INPI 2019 e 2020

Percebe-se que a Universidade de São Paulo, apesar de gerar o maior número de publicações no período estudado (Gráfico 1), não é a universidade que gera maior número de proteções da propriedade intelectual (Gráfico 5). Outro detalhe que pode ser observado é que a Universidade Federal de Alagoas (UFAL), não é uma instituição que aparece entre as instituições com maior número de publicações (Gráfico 1), mas é a instituição que aparece com o maior número proteções de novas tecnologias (Gráfico5). Tanto os conhecimentos gerados na USP como as tecnologias desenvolvidas na UFAL provavelmente contribuíram com o número de proteções (Gráfico 5) que foram realizadas pelos estados de São Paulo e Alagoas.

Referentes aos estados brasileiros com o maior número de depositantes, São Paulo, Paraná e Bahia, lideram com 66, 44 e 26 depósitos respectivamente. (Gráfico 6).

Gráfico 6. Número de patentes depositado estados brasileiros relacionados aos produtos da cadeia apícola entre os anos de 2000 a 2019.

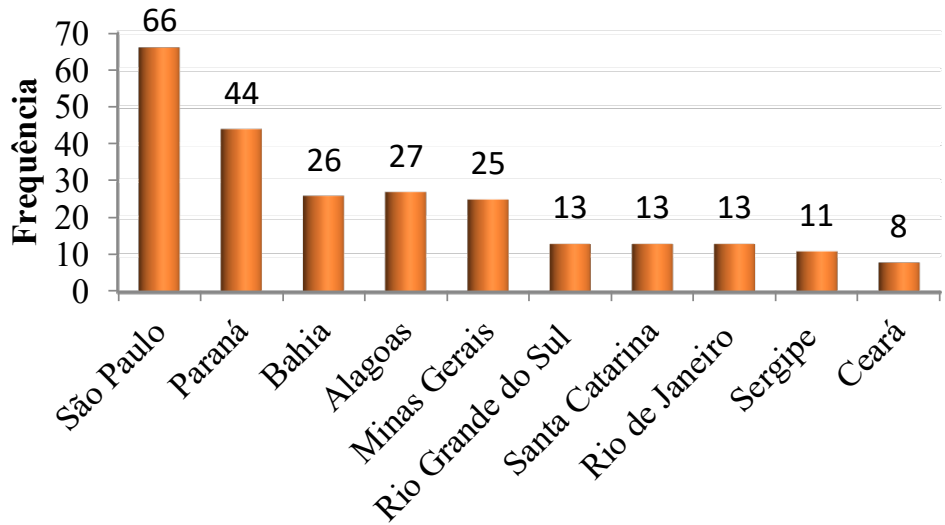

Fonte: INPI, 2019 e 2020.

No que se refere às áreas de aplicação dos produtos oriundos da cadeia apícola, no período de 2000 a 2019 , os resultados apontam a saúde (162 registros como a área de maior aplicabilidade dos produtos e processos oriundos dos produtos da cadeia apícola, seguida pela indústria alimentícia (89 registros)). Através da classificação CIP é possível averiguar que a indústria alimentícia abrange desde a preparação, modificação e conservação dos alimentos. A agricultura (40 registros), além 
de equipamentos para maximizar a produção e coleta dos produtos apícolas pesquisadas, abrange a produção de biocidas, repelentes e substratos, a indústria química (24 registros) engloba produção de fertilizantes, velas, lubrificantes, ceras, vinhos, cervejas e vinagre, a saúde trata de preparações medicinais e farmacêuticas, além de produtos para beleza.

\section{Situação Legal dos pedidos de patentes no Instituto de propriedade Intelectual (INPI).}

Os resultados obtidos, demonstram os pedidos de patentes arquivados é maior que os concedidos, o que não configure como resultado positivo. O número alto de patentes arquivadas pode estar relacionado a dois fatores, o primeiro seria que os produtos desenvolvidos não foram atrativos para o mercado e foram abandonadas e o segundo fator seria a falta de interesse ou falta de capacidade de percepção da importância do desenvolvimento de inovação e da respectiva proteção para o desenvolvimento profissional, da instituição ou do país (Gráfico 7).

Gráfico 7. Situação legal dos pedidos de patentes no período de 2000 a 2019.

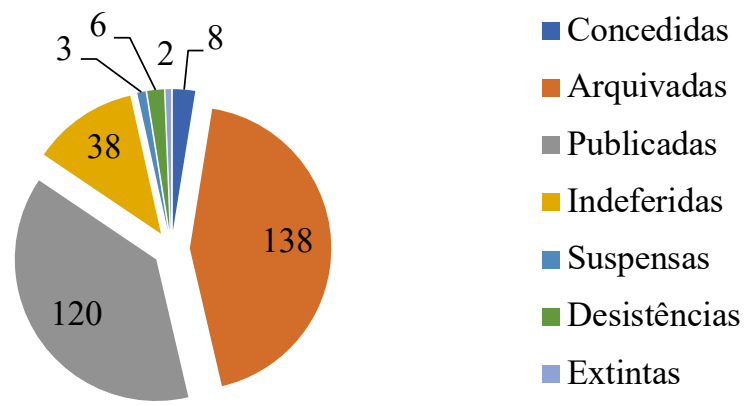

Fonte: INPI 2019 e 2020. Fonte: INPI: 2019 e 2020.

Quanto aos documentos de patentes arquivados, a situação ocorreu em sua grande maioria entre os anos 2000 a 2008. Os arquivamentos foram por falta de pagamento de anuidades e também, por falta de cumprimento de exigências dentro do prazo legal. Nota-se que a falta do recolhimento da anuidade é o maior fator para arquivamento dos pedidos de patentes. Os depositantes independentes possuem o maior número de pedidos de patentes arquivadas, seguidos de empresas.

Pelo Brasil ser signatário de acordos internacionais, é permitido que indivíduos e empresas estrangeiras depositem pedidos no país. Uma maneira que o INPI utiliza para identificar os depositantes é a separação de pedidos e concessões feitas no Brasil entre residentes e não residentes no Brasil.

Os resultados demonstram um baixo número de depósitos de patentes no Brasil e ainda menor de depósitos de não residentes no país. Os resultados observados são, provavelmente, pela falta de percepção do país da importância do desenvolvimento de novas tecnologias e também por algum motivo pode ser percebido que ocorre desinteresse de empresas ou outros depositantes internacionais de proteção de produtos no Brasil

Dentre patentes concedidas, quatro utilizam a própolis como matérias primas, duas foram pleiteadas por inventores, uma por empresa e outra parceria entre universidade e Empresa, nos anos de 2004, 2006, 2012 e 2013 respectivamente (PI 0400975-4 A2; PI 0605769-1 B1; BR 1020120199505 B1; BR 1020130184926 B1). A utilização do mel na indústria alimentícia propiciou uma patente para a UNICAMP, no ano de 2012 (BR 1020120162130 B1). Com utilização da cera como matéria prima, no ano 2000 uma empresa localizada na Grã Bretanha, teve seu pedido de patente concedido na área química (PI 0112174-0 B1). Na indústria cosmética foram concedidas duas patentes para uma mesma empresa localizada na Holanda (PI 0415150-0 B1; PI 0508137-8 B1). 


\section{Produtos registrados no Escritório Latino Americano de Patentes (LATIPAT)}

A partir da pesquisa utilizando a Classificação Internacional de Patentes e palavras chaves selecionadas na base de dados do LATIPAT, foram encontrados quinhentos e sessenta e um documentos de patentes depositados referente às matériasprimas da cadeia apícola.

Após análise dos resultados foram observadas oscilações na quantidade de depósitos de documentos de patentes, referentes aos produtos apícolas. O mel apresentou maiores resultados nos anos de 2008 e 2013 com treze publicações e a própolis atingiu o máximo no ano 2018 com dezoito publicações.

Os depósitos de patentes com uso de matéria prima geleia real ocorreu nos anos de 2000 a 2005, ficando inerte até 2011 que teve um depósito de documentos de patentes.

Patente de produtos de cera teve pedidos de depósitos durante todo o período estudado, mas o ápice ocorreu em 2001 com cindo depósitos. O primeiro depósito de pedidos relacionado ao pólen ocorreu no ano de 2009 não havendo novos pedidos até 2012, neste ano, 2014, 2016 e 2018 houve um pedido para cada ano. No ano de 2017, houve a maior quantidade pedidos, quatro. Referente à apitoxina, no ano de 2003 foi efetuado um depósito de pedido de patente, nos anos 20011, 2012,2017 e 2018 surgiu um depósito por ano.

Os inventores efetuaram o maior número de pedidos de patentes no período de 2000 a 2019 , seguido pelas universidades. As empresas ocupam terceiro lugar em quantidade de depósitos de documentos de patentes. Dentre as universidades, foi observado que cinco são estrangeiras e das empresas vinte oito se localizam fora do Brasil (Gráfico 8).

A análise dos resultados considerando o tipo de depositante é de suma importância para avaliar onde estão concentrados os investimentos em P\&D (Pesquisa \& Desenvolvimento) responsáveis por gerar inovação.

Gráfico 8. Depósitos de patentes relacionados aos produtos apícolas por tipo de depositante no período de 2000 a 2019.

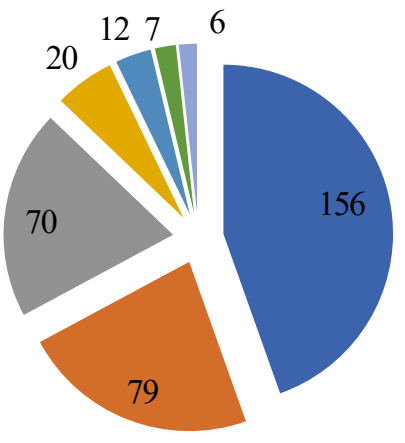

Depositantes independentes

Universidades

Empresas

Universidades/Empresas

Empresas/Empresas

Institutos de

Pesquisas/Universidades

Fonte: LATIPAT 2019 e 2020.

No Gráfico 9, é possível verificar o total de documentos de patentes depositados entre os anos 2000 a 2019, 44\%dos pedidos foram solicitados por inventores independentes, seguido pelas universidades com $23 \%$ e as empresas com $20 \%$. As parcerias permitem identificar que as Universidades e empresas respondem por $6 \%$ do total de depósitos de documentos de patentes. Esses resultados demonstram que as pesquisas relacionadas aos produtos e processos com utilização de matérias primas da cadeia apícola estão concentradas em menor número as universidades e empresas.

O baixo número de depósito por empresas pode ser explicado por vários fatores, depósito ter como titular o proprietário da empresa, para resguardar o direito do bem material em caso de futuras negociações que envolveria a empresa, pelo desinteresse da indústria nas tecnologias relacionada aos produtos apícolas, demora entre o depósito e a concessão da patente ou até mesmo o alto custo da manutenção do processo de pedido de patentes. Além disso, no que diz respeito à 
concorrência externa a presença empresarial deveria predominar o sistema de patentes, igual ocorre nas potências econômicas mundiais.

Quanto às universidades, provavelmente as atividades de pesquisas podem ser restringidas para tecnologias que envolvem a cadeia apícola, quando comparadas a outras que contribuem com um maior retorno financeiro ou também por falta de incentivo fiscal.

Dentre as instituições de ensino detentoras a tecnologia estudada a Universidade Federal de Alagoas é a que mais se destaca com treze depósitos de documentos de patentes o que corresponde a $12 \%$ do total depositado, seguida pela Universidade Federal do Paraná com doze depósitos equivalentes a $11 \%$ e a Universidade Estadual de Maringá com onze depósitos ou 10\% (Gráfico 10).

Gráfico 9. Número de depósitos de documentos patentes com utilização de produtos da cadeia apícola de 2000 a 2019 de diferentes instituições.
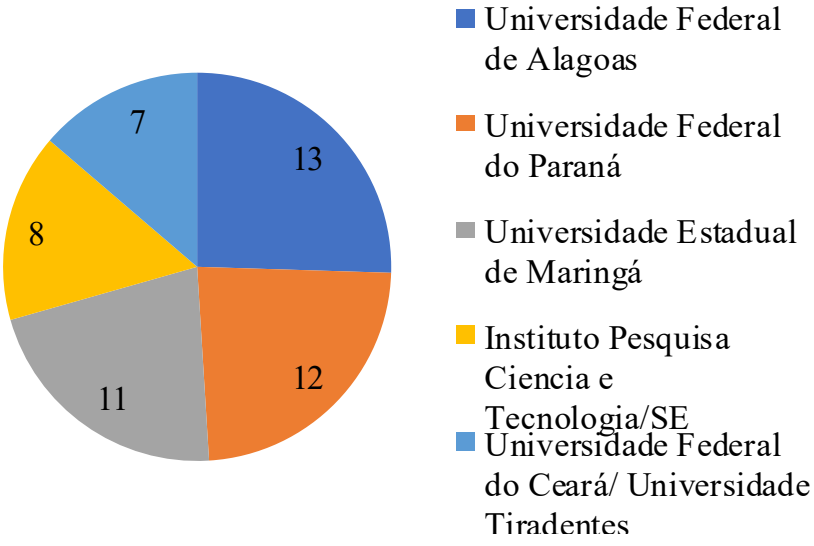

Fonte: LATIPAT 2019 e 2020.

Em relação aos países nos quais se originou a tecnologia patenteada, é possível constatar que a maior parte das tecnologias se encontra distribuída em nove diferentes países. Dentre os países detentores da tecnologia patenteada no LATIPAT, o Brasil é o que mais se destaca com trezentos e sete documentos de patentes depositados, seguidos pelos Estados Unidos com quinze e Espanha com dez documentos de depósito (Gráfico 10). 
Gráfico 10. Países com depósitos de patentes com utilização de produtos apícolas no período de 2000 a 2019.

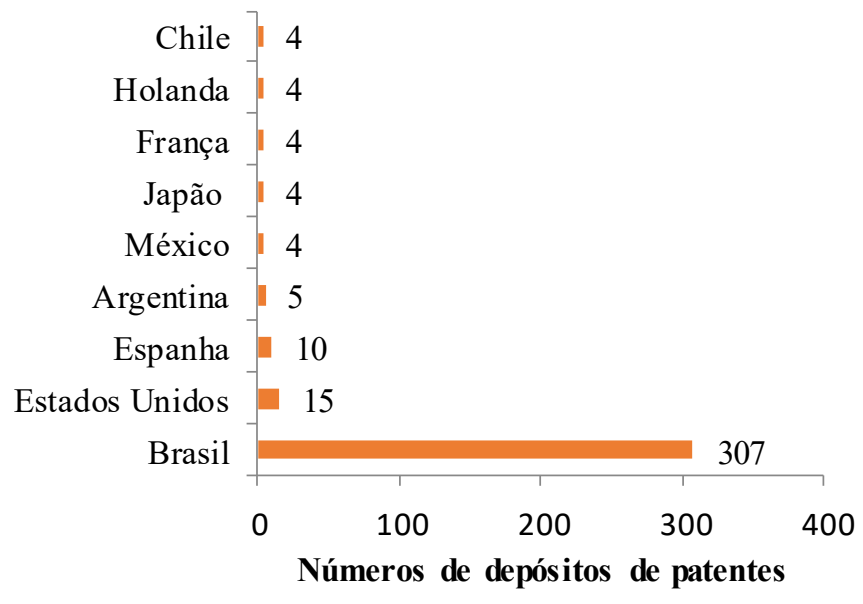

Fonte: LATIPAT, 2019 e 2020.

Do total de documentos, $47 \%$ dos documentos de patentes depositados no LATIPAT estão relacionados à área da saúde, que se divide em cosmética, farmacêutica e preparações medicinais em seguida está a Indústria de alimentos com $36 \%$ dos documentos depositados, seguido pela área de agricultura com $9 \%$ do total de documentos de patentes depositados (Gráfico $11)$.

Gráfico 11. Áreas tecnológicas de aplicação de produtos da cadeia apícola e tecnologias correlatas no período de 2000 a 2019.

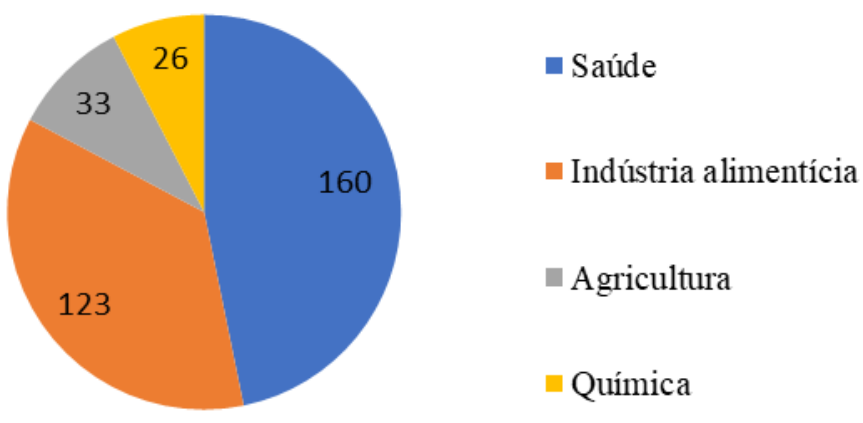

Fonte: LATIPAT 2019 e 2020.

\section{Produtos registrados no Escritório Europeu de Patentes (ESPACENET).}

A partir da análise dos documentos de patentes de produtos e processos com utilização de produtos apícolas, após exclusão dos documentos que não se referiam diretamente as tecnologias pesquisadas, foram identificados 1722 processos para o mel, 3778 para própolis, 2071 cera, 1882 documentos referentes à geleia real, 855 para pólen e 324 para apitoxina. Entretanto, vale esclarecer que os dados coletados nesta pesquisa podem não corresponder ao número real. Apesar de ser uma base de dados muito abrangente, o ESPACENET somente permite visualizar até o limite de quinhentos documentos, além disso, o mesmo pedido pode estar descrito em mais de um código CIP.

Os resultados revelam que os pedidos de patentes sofreram oscilações no período estudado. Observa-se a própolis em destaque, no entanto seu ápice foi no ano de 2014, voltando a oscilar desde então. A cera e geleia real superaram o mel na quantidade de depósitos de documentos de patentes a partir do ano de 2014. A apitoxina apresentou um maior número de depósitos no ano de 2014. Foi observado nos resultados que os produtos apícolas são muito utilizados no cenário internacional, ao contrário do que ocorre no Brasil, onde as inovações focam no mel e na própolis. 
A saúde é a área de maior aplicabilidade dos produtos oriundos da cadeia apícola e representa $52 \%$ do total de depósitos de pedidos de patentes, seguido pela indústria alimentícia com $32 \%$ do total das aplicações (Gráfico 12). Ressalta-se que os produtos indicados como pertencentes à indústria veterinária se referem a alimentação e saúde animal.

Gráfico 12. Áreas tecnológicas de aplicação de produtos da cadeia apícola e tecnologias correlatas no período de 2000 a 2019.
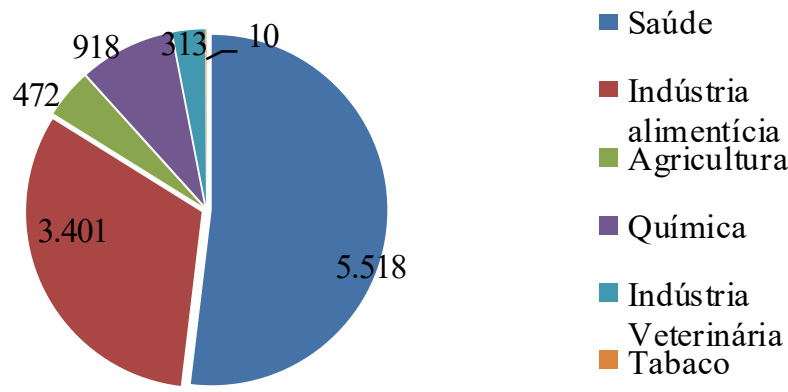

Fonte: ESPACENET 2019 e 2020.

Os processos referentes ao mel, pólen e geleia real são voltados para a área alimentícia enquanto a própolis e a cera são utilizados principalmente para a área da saúde que também envolve a produção de cosmético. Os depósitos referentes à apitoxina são majoritariamente na área da saúde nas preparações medicinais, é utilizada também na indústria química, fabricação de vinhos e na agricultura para produção de biocidas.

Diante das informações, nota-se o interesse mundial pelas propriedades dos produtos apícolas notadamente pelas empresas privadas, entretanto, há muito ainda a ser feito principalmente no que se refere á profissionalização dos produtores para que alcancem uma visão empreendedora de tudo que uma colmeia pode oferecer, sem degradar o ambiente.

As empresas detêm o maior número de depósitos de pedidos de patentes, seguidas pelos depositantes independentes ou inventores e universidades (Gráfico 13).

Gráfico 13. Depósitos de patentes junto ao ESPACENET relacionados aos produtos apícolas por tipo de depositante no período do ano 200 a 2019.

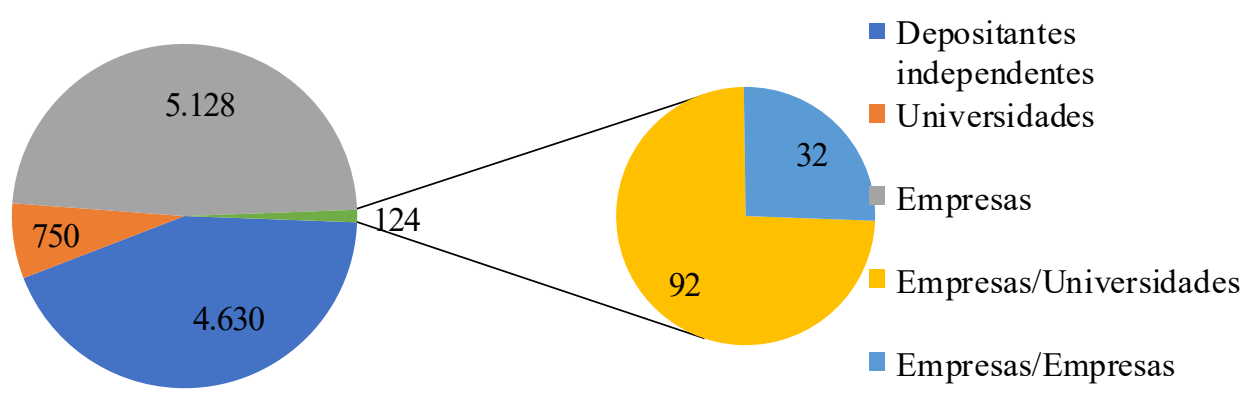

Fonte: ESPACENET 2019 e 2020.

A efetiva participação de empresas no cenário das patentes é um diferencial. Segundo de Campos e Denig (2011) as grandes empresas das nações mais desenvolvidas na busca por lucros e liderança de mercado investem mais intensivamente em 
pesquisa e desenvolvimento, e, consequentemente, os resultados são melhores no desenvolvimento tecnológico. Os resultados, referente aos países detentores de tecnologias estudadas, revelam que os países asiáticos são os principais depositantes da área tecnológica de interesse (Gráfico 14).

Gráfico 14. Número de depósitos de documentos de patentes, por país de origem dos depositantes, entre o ano 200 a 2019.

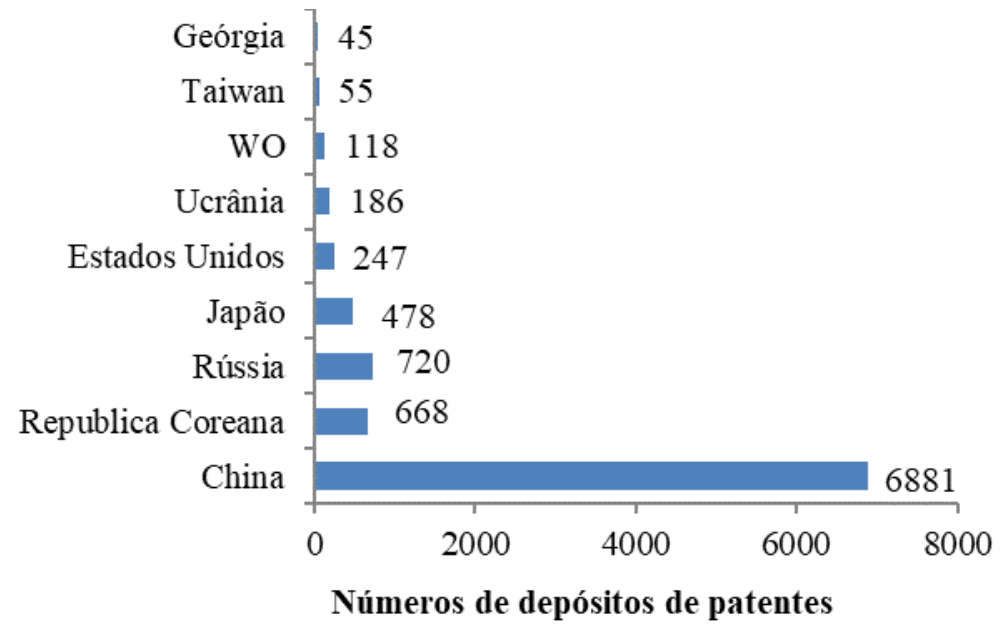

Fonte: ESPACENET 2019 e 2020.

\section{Conclusão}

Os resultados obtidos na pesquisa demonstram que a apicultura é uma atividade lucrativa, principalmente nos países asiáticos que exploram todos os produtos apícolas e possuem apoio da iniciativa privada. Os depósitos de patentes contribuem para indicar a capacidade de inovação de um país além de demonstrar as oportunidades que poderão ser exploradas no futuro por seus detentores.

O Brasil, mesmo sendo considerado um país atuante na produção de produtos e processos de produtos da cadeia apícola, não de sobressai no mercado internacional. Um dos grandes desafios enfrentados pelo setor apícola brasileiro é o desenvolvimento tecnológico, visto que essa atividade em grande parte se desenvolve pela agricultura familiar. Outro fator importante é a necessidade de pesquisas em outros segmentos econômicos, visto que a maioria das inovações se volta principalmente para a indústria alimentícia e saúde, o que contribui para a estagnação da exploração de outras propriedades presentes nestes produtos.

Neste contexto, faz-se necessário o desenvolvimento de políticas públicas, incentivos fiscais e capacitação dos produtores, para que desenvolvam um espírito competitivo, capaz de inovar para além de agregar valor aos produtos, explorar ao máximo os produtos gerados pela cadeia apícola.

\section{Referências}

Adaškevičiūte, V., Kaškonienė, V., Kaškonas, P., Barčauskaitė, K., \& Maruška, A. (2019). Comparison of physicochemical properties of bee pollen with other bee products. Biomolecules, 9(12), 819. 10.3390/biom9120819;

Bommuraj, V., Chen, Y., Klein, H., Sperling, R., Barel, S., \&Shimshoni, J. A. (2019). Pesticide and trace element residues in honey and bees wax combs from Israel in association with human risk assessment and honey adulteration. Food Chemistry, 299, 125123. 10.1016/j.foodchem.2019.125123.

Brasil. Lei $\mathrm{n}^{\circ}$ 9.279, de 14 de maio de 1996. Regula os direitos e obrigações relativos à propriedade industrialhttp://www.planalto.gov.br/ccivil_03/leis/L9279.htm.

Burgut, A. (2019). Effects of propolis extracts on biogenic amine production by food-borne pathogens. Kafkas Üniversitesi Veteriner Fakültesi Dergisi, 26(2). 10.9775/kvfd.2019.22718; 
Conto, S. M. D., Antunes, J. A. V., \& Vaccaro, G. L. R. (2016). A inovação como fator de vantagem competitiva: estudo de uma cooperativa produtora de suco e vinho orgânicos. Gestão \& Produção, 23, 397-407. 10.590/ 0104-530X1677-14;

de Campos, A. C., \& Denig, E. A. (2011). Propriedade intelectual: uma análise a partir da evolução das patentes no Brasil. Revista Faz Ciência, 13(18), 97.

de Souza, J. A., de Souza, E. F. M., Modro, A. F. H., Porto, W. S., \& de Lima Oliveira, D. (2016). A apicultura em Rondônia (Amazônia Legal): estudo de caso sobre o arranjo produtivo local da apicultura no cone sul. Revista Estudo \& Debate, 23(2).

Espacenet. European Patent Office (EPO). https://wordwide.espac.

Fernandes Júnior, J. V. M., \& Silva, N. G. A. (2016). Cadeia produtiva do mel: um estudo no município de Pau dos Ferros/RN. Revista Eletrônica em Gestão, Educação e Tecnologia Ambiental Santa Maria, 20, (1), jan.-abr., p. 115-124;

Iegaki, N., Narita, Y., Hattori, N., Hirata, Y., \&Ichihara, K. (2020). Royal jelly reduces depression-like behavior through possible effects on adrenal steroidogenesis in a murine model of unpredictable chronic mild stress. Bioscience, biotechnology, and biochemistry, 84(3), 606-612. 10.1080/09168451.2019.1691496;

INPI. Instituto Nacional de Propriedade Industrial. http://ipc.inpi.gov.br/ipcpub/.

LATIPAT. América Latina e Espanha. https: //lp.espacenet.com/.

Martinez, O. A., \& Soares, A. E. E. (2012). Melhoramento genético na apicultura comercial para produção da própolis. Revista Brasileira de Saúde e Produção Animal, 13, 982-990.

Vieira e Medeiros, et al. (2020). Atividades cientificas e tecnológicas desenvolvidas com Arecaceae. Revista Brasileira de Gestão Ambiental e Sustentabilidade. 7(17) (2020). 10.21438/rbgas(2020)071719

Monteiro, E. S., Khan, A. S., \& de Sousa, E. P. (2015). Índice de inovação e aprendizagem e seus fatores condicionantes do Arranjo produtivo local de apicultura no nordeste paraense. RAI Revista de Administração e Inovação, 12(3), 251-267.

Mueller, S. P. M., \& Perucchi, V. (2014). Universidades e a produção de patentes: tópicos de interesse para o estudioso da informação tecnológica. Perspectivas em Ciência da Informação, 19, 15-36.DOI/10.1590/1981-5344/1828;

Pascoal, A., Estevinho, M. M., Choupina, A., Sousa-Pimenta, M., \& Estevinho, L. M. (2019). An overview of the bioactive compounds, therapeutic properties and toxic effects of apitoxin. Food and Chemical Toxicology, 134, 1-11. 10.1016/j.fct.2019.110864110864;

Queiroga, C. F. M. A., Leite Filho, F. G., Machado, A. V., \& de Oliveira Costa, R. (2015). Cadeia Produtiva do Mel de Abelhas: Fonte Alternativa de Geração de Renda para Pequenos Produtores e Qualidade Físico-química do Mel. Revista Brasileira de Agrotecnologia, 5(1), 24-30.

Romero, M., Freire, J., Pastene, E., García, A., Aranda, M., \& González, C. (2019). Propolis polyphenolic compounds affect the viability and structure of Helicobacter pylori in vitro. Revista Brasileira de Farmacognosia, 29, 325-332.DOI.org/10.1016/j.bjp.2019.03.002

Vidal, M. D. F. (2018). Produção de mel na área de atuação do BNB entre 2011 e 2016.

Vieira, R. P; Fernandes, M (2016). Estudo da cadeia produtiva do mel no municipio de Orizona - Goiás. Revista Brasileira de Produtos Agroindustriais. Campina Grande, 18(1), 81-89;

Web of Science. https:/www-webofscience.ez27.periodicos.capes.gov.br/wos/woscc/basic-search.

Wolf, L. F. (2018). Sistema de produção de mel para a região sul do Rio Grande do Sul / Pelotas. Embrapa. Clima Temperado. 88 p. 